\title{
MEASURING SOCIAL CAPITAL IN PLANNED AND UNPLANNED NEIGHBORHOODS OF LAHORE: A CASE STUDY OF JOHAR TOWN AND SINGHPURA
}

\author{
Saima Gulzar* \\ Muhammad Asim** \\ Rumana Khan Shirwani***
}

\begin{abstract}
Social capital is an asset and is defined as the social networks and interactions that inspire trust and reciprocity among citizens necessary for the community development. The fundamental premise is that some neighborhood designs enable or encourage social ties or community connections, whereas others do not. Two case studies were selected, namely Singhpura (traditional settlement) and Johar Town (modern settlement) to measure the social capital in Lahore. Questionnaire was designed to conduct surveys at household level to measure social capital. Surveys were conducted among 154 respondents belonging to both areas. Statistical analysis of the data collected was done using the SPSS software.
\end{abstract}

It was concluded that over the past few years, social capital in the neighborhoods of Lahore and different areas of Pakistan has decreased to a great extent. The design of neighborhoods promotes dependency on the private vehicles. Walkability decreases in planned areas but it is still available in unplanned old developed areas because of mixed land uses. Due to high level of walkability in these areas, social interaction is high as compared to planned areas and high income societies, where people have no value of social interaction and are busy in their personal work. In developed countries due to high social capital people participate in community level development projects, but in the case of Pakistan due to low level of social capital there is no concept of participatory development.

It has been recommended here that new developments should follow the traditional urban forms where traditional neighborhood developments should be based on new urbanism principles, which encourage the use of undulating and straight streets that maximize pedestrian connectivity. These new developments should be a mix of compatible land uses and should work to incorporate elements such as architectural details and street furniture, encouraging human interaction on an urban scale.

Keywords: Social Capital, Neighborhood, Traditional, Lahore.

\section{INTRODUCTION}

Social capital is little understood, very difficult to measure and not easy to rigorously define. Putnam (2000) defines it as "features of social organization such as networks, norms, and social trust that facilitate coordination and cooperation for mutual benefit" (Baron, et. al., 2000: 121). In the case of Pakistan, mostly people are not willing to participate in any development project due to lack of trust and coordination amongst each other. Mostly people prefer personal interest over community benefits. They have the concept that it is the responsibility of the government to provide all basic facilities. In the literature review the following points were concluded with reference to social capital and planning activities (Haq, 2010; Harper, 2002; Coleman, 1988):

- Any society bears a high financial and social cost for crime and other anti-social behavior. These costs are incurred by society in preventing crime, providing justice, infrastructure, repairing criminal damage, supporting victims, and dealing with offenders. High crime rates can also diminish social resources as lack of community trust, confidence and freedom, and an overall climate of fear may overwhelm or replace the spirit of cooperation and participation in community life.

\footnotetext{
* Dr. Saima Gulzar, Associate Professor, Department of Architecture and Planning, School of Architecture and Planning, University of Management and Technology, Lahore, Email correspondance: saima.gulzar@umt.edu.pk ** Dr. Muhammad Asim, Assistant Professor, City and Regional Planning Department, University of Engineering and Technology, Lahore, Email correspondance: asim_planner@yahoo.com

*** Rumana Khan Shirwani, Assistant Professor, School of Architecture and Planning, University of Management and Technology, Lahore, Email correspondance: rumana.shirwani@umt.edu.pk
} 
- People do not find time for meetings and participation in local activities.

- People lack the ability of working together, because of lack of trust and ability to work in groups.

- People are unable to carry out any development projects at the community level.

- Community members have a weak structure relationship as they don't know about their neighbors. They are not in contact with each other.

- People mostly use their private vehicles. Dependency on vehicles is increasing thus, people find no chance of interacting with others.

- People stay in poverty because they don't have social networks.

- There is less contact with family and friends.

- Suburbs of the city also reduce social capital. Some factors of suburbs, like heavy vehicular movement and planning patterns, reduce social interaction.

- Sometimes the planning of communities plays an important role to create sense of safety. If the planning is not good then people resist going outdoors as they feel insecure.

The basic objective outlined for this study is to find out how planning can enhance social capital within a community and identify factors for declining social capital. This study also highlights the contribution of the physical environment that helps promote social capital in addition to the identification of neighborhood design which enhances social capital.

\section{MATERIALS AND METHODS}

An integrated research methodology was developed for measuring the social capital and its impact on planning after studying different social capital measuring techniques used globally (Coleman, 1994, 1988; Pretty and Ward, 2001; Scheffert, 2009). The questionnaire survey was conducted for collecting the information from the residents of selected case study areas (planned and unplanned areas) as described below.

\section{Case Studies}

Lahore is the capital city of the province of Punjab, the second largest metropolitan area in Pakistan and $16^{\text {th }}$ most populous city in the world. It is an important historical center in South Asia. With a rich history dating back over a millennium, Lahore is a main cultural center of the Punjab region and is the largest Punjabi city. One of the most densely populated cities in the world, Lahore remains an economic, political, transportation, entertainment and educational hub of Pakistan. To measure the social capital in Lahore, neighborhoods were subjectively categorized into two ideal types by the researcher before conducting the survey. One is a planned neighborhood and the other was an unplanned neighborhood. The neighborhoods selected and surveyed included the following.

\section{Johar Town}

Johar Town is a wealthy neighborhood of Lahore (Figures1, 2). It is named after Mohammad Ali Johar, one of the leaders of the Pakistan Movement. In 1981 the land was acquired by Lahore Development Authority (LDA) in order to plan a scheme by the name of MA Johar Town which is situated in the south west of Lahore. The scheme was launched in the year 1986. It consists of two phases; Johar Town phase 1 and Phase 2. Johar Town phase 1 is taken as a case study area for this research. It is a planned neighborhood with most of the people living here belonging to high income group and dependent on cars.

\section{Singhpura}

Singhpura is one of the oldest neighborhoods of Lahore located along G. T. Road near University of Engineering and Technology, and it is located at the north eastern side of Lahore (Figures 3,4). It is an unplanned area and one of the oldest neighborhoods of Lahore. Most of the people living here belong to low and middle income groups. Residents living in this neighborhood mostly walk to parks, local schools and workplace. In Singhpura there is high connectivity of streets and most of the streets have corner shops so all the residents easily walk to the shops for the purchase of daily goods.

\section{Selection of sample size}

The total sample size was calculated by applying the sample size formula on the total number of households of Johar Town and Singhpura. The total sample size was then proportionally distributed in the case study areas on the basis of population of the particular areas. A total number of 154 questionnaires were filled from the case study areas; 104 from Johar Town and 50 from Singhpura (Table-1). 


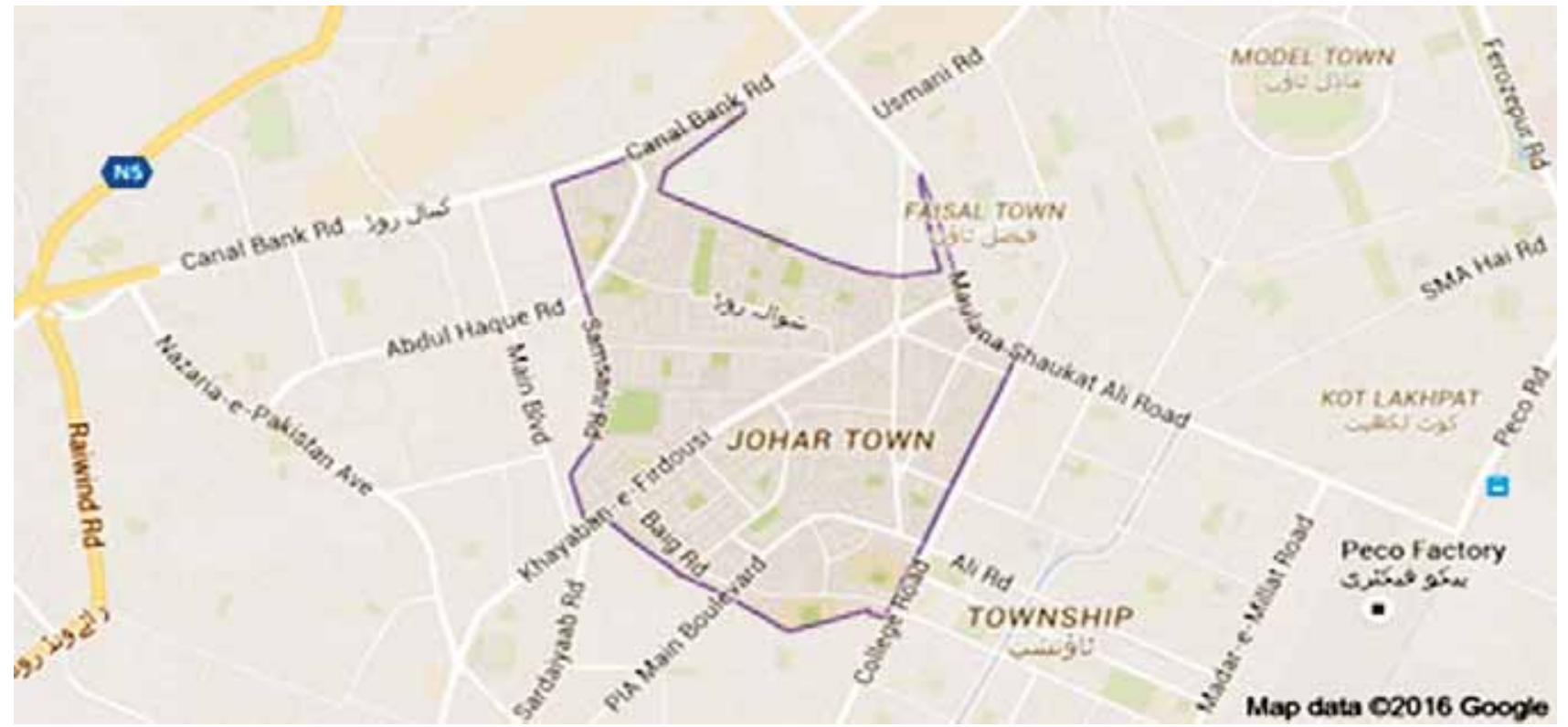

Figure-1: Location map of Johar Town.

Source: www.googlemaps.com accessed 27/3/2015

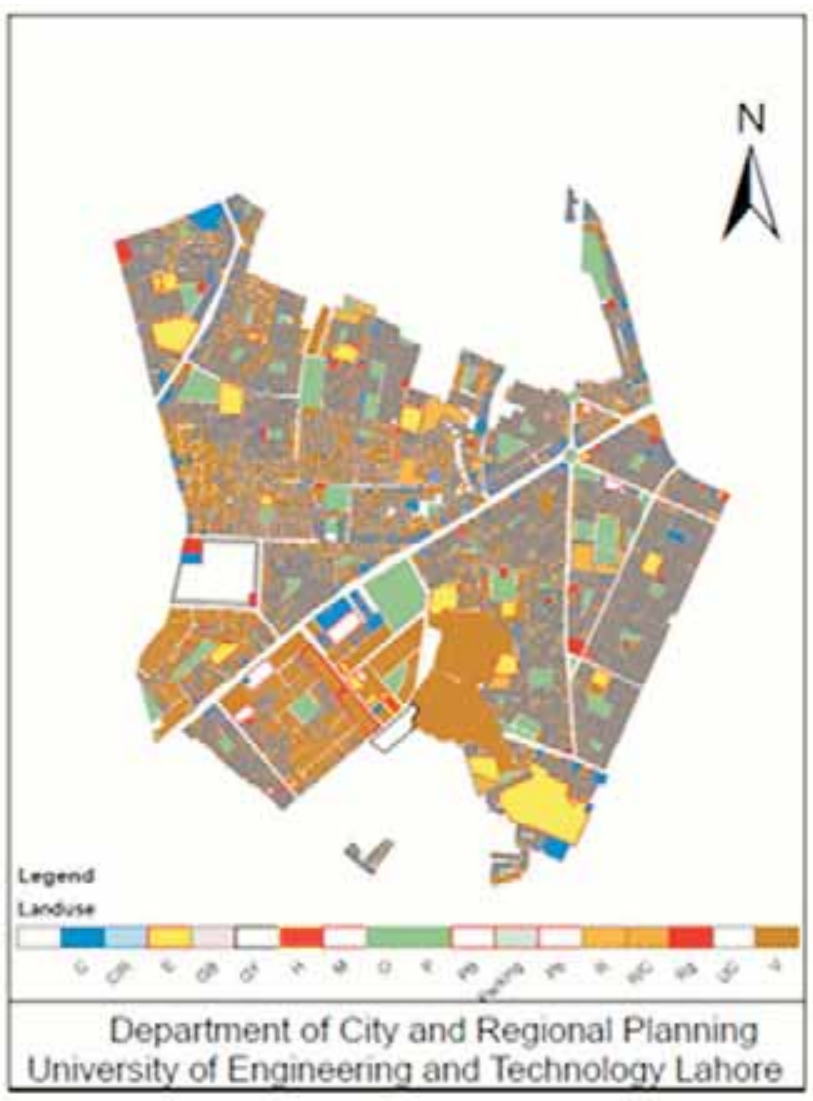

Figure-2: Land Use Map of Johar Town

Source: www.googlemap.com accessed 27/3/2015.

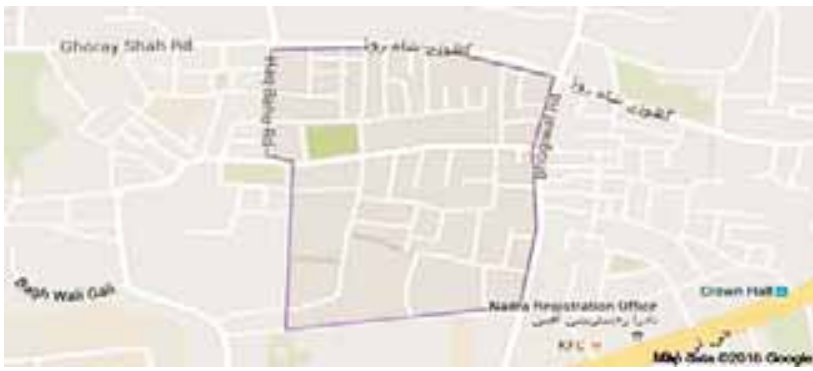

Figure-3: Location map of Singhpura.

.Source: www.googlemaps.com accessed 27/3/2015

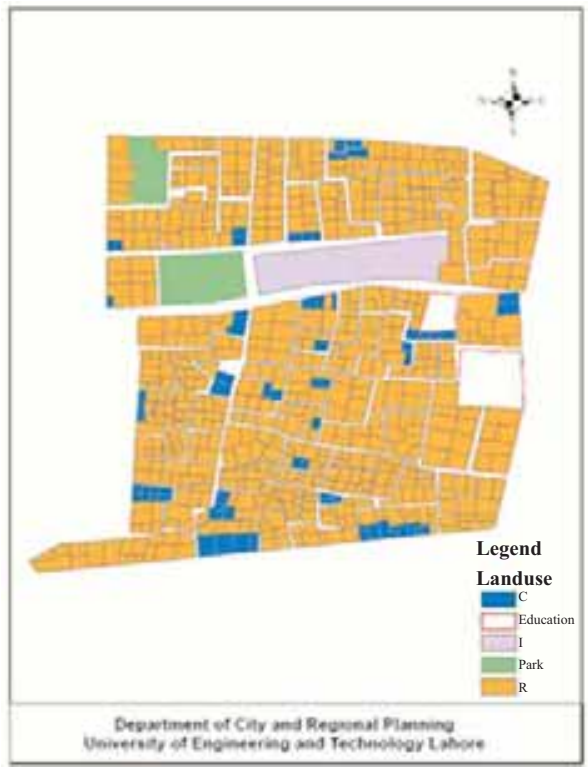

Figure-4: Land Use Map of Singhpura. 
Table-1: Area wise distribution of sample size.

\begin{tabular}{|l|c|c|c|}
\hline \multicolumn{1}{|c|}{ Case Study } & Johar Town & Singhpura & Total \\
\hline No. of Households & 8463 & 4100 & 12563 \\
\hline Expected Error (e) & 0.011 & 0.016 & 0.08 \\
\hline Sample Size & 4231.5 & 2050 & 154.3305 \\
\hline Proportional Sample Size & 103.964 & 50.367 & 154.331 \\
\hline
\end{tabular}

\section{Questionnaire Survey}

Questions were formulated to accommodate all the factors of social capital like trust, social interaction, community participation, walkability and other parameters through which level of social capital within a community can be measured. The questionnaire was designed to measure social capital using both close and open ended questions in planned and unplanned areas. After the questionnaires were filled by respondents an analysis was undertaken.

\section{Data Collection and Interpretation}

The comparative data analysis technique using Microsoft Excel and SPSS were used to interpret the collected data.

\section{Conclusions and Recommendations}

All the data gathered through the conducted primary surveys was analysed and the conclusion and recommendations were established on the basis of results formulated.

\section{RESULTS AND DISCUSSIONS}

The social capital refers to the institutions, relationships, and norms that shape the quality and quantity of a society's social interactions. Research in this field already showed that social cohesion is critical for societies to prosper

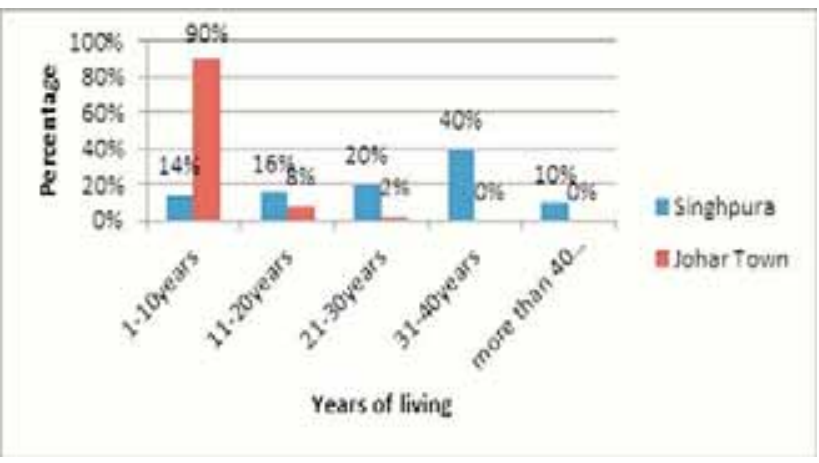

Figure-5: Years of living in neighborhood. economically and for development to be sustainable. Social capital is not meant just for the sum of the institutions which underpin a society. It is the binding agent that reinforces the society's interaction and holds it together for common future. Communities with higher levels of social capital benefit from better quality of life. More specifically the case studies generated the following results:

\section{Socio-economic Data}

The questionnaire included questions about how long the residents had been living in the neighborhoods. Most of the respondents living in Singhpura replied that they were living there for about 30 to 40 years, while $90 \%$ of the residents in Johar Town replied that they had been living there for about 1-10 years (Figure 5).

\section{Income level}

This chart indicates that the majority of the population in Johar Town had an income between the range of Pak Rupees 51,000 to 75,000 per month. But the majority of the population in Singhpura had an income level between Pak Rupees 25,000 to 50,000 per month. This showed that Johar Town residents had high income levels as compared to residents of Singhpura (Figure 6).

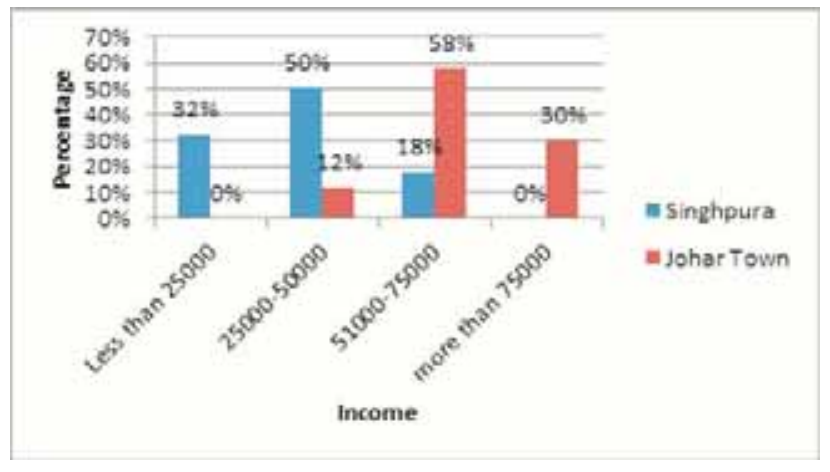

Figure-6: Income of head of household. 


\section{Occupation of Head of Household}

These statistics showed that $42 \%$ of the people in Singhpura had their businesses, like grocery shops and $24 \%$ people had government jobs. But in the case of Johar Town, 48\% people had high level government jobs. The difference in the type of occupation of the head of the household impacted on the presence of social capital in each neighborhood (Figure 7).

\section{Transportation}

\section{Average distance from the house to the school and the mode of transport used}

These statistics show that the distance from the house to the school in Singhpura is less than $1 \mathrm{~km} .84 \%$ people said they have schools near their homes. Therefore, they mostly used bikes or walked on foot for going to school. $14 \%$ of the people used motor cycles and $58 \%$ people went to school on foot (Figure 8). But in Johar Town 48\% people said that they travelled between $1-3 \mathrm{~km}$ from their houses to the schools and $32 \%$ people travelled $4-6 \mathrm{~km}$ to reach the school. These people used their personal vehicles for travelling to schools and colleges. 54\% people used their cars for going to their schools and colleges (Figure 9).

Average distance from the house to the work place and mode of transport used for getting to the work place

These statistics show that in Singhpura mostly people travelled an average distance of 4-6 kms to reach their workplace but in Johar Town $40 \%$ of the respondents said they travelled 4-6kms to reach their workplace and sometimes more than $9 \mathrm{kms}$, so they mostly used their personal vehicles like cars. In Singhpura some people travelled less than $1 \mathrm{~km}$ to get to their workplaces so they went by foot or on their bikes (Figures 10 and 11).

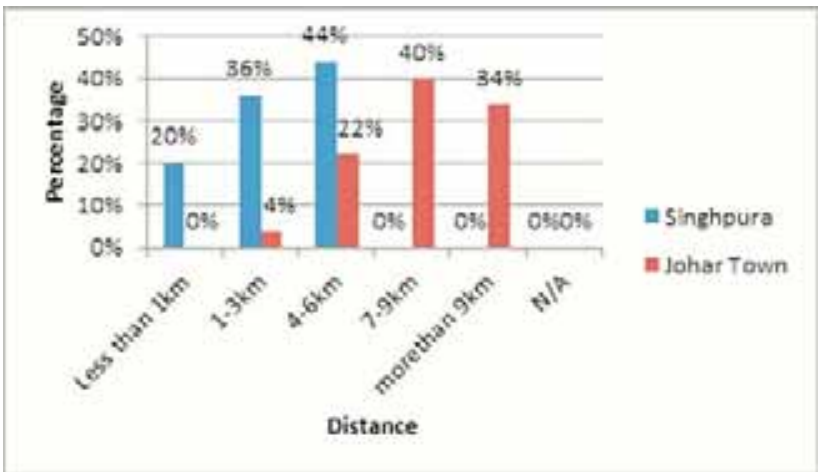

Figure-10: Average distance from house to workplace.

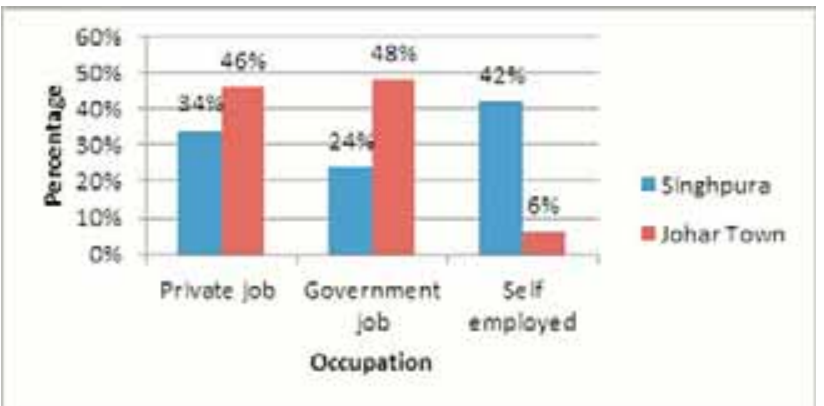

Figure-7: Occupation of head of household.

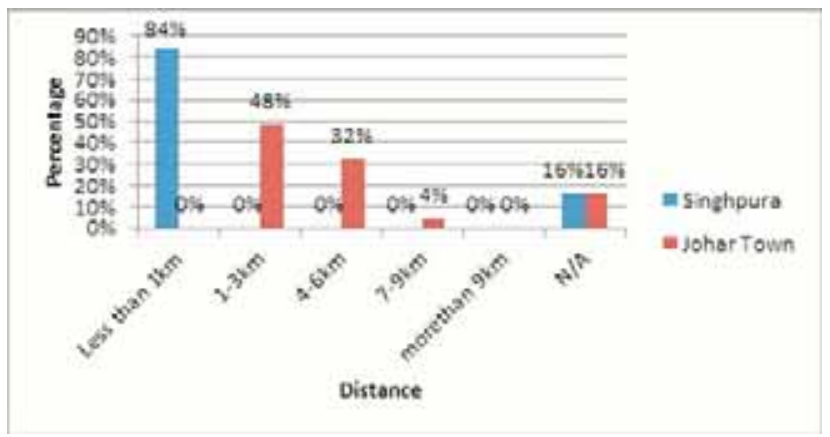

Figure-8: Average distance from house to school.

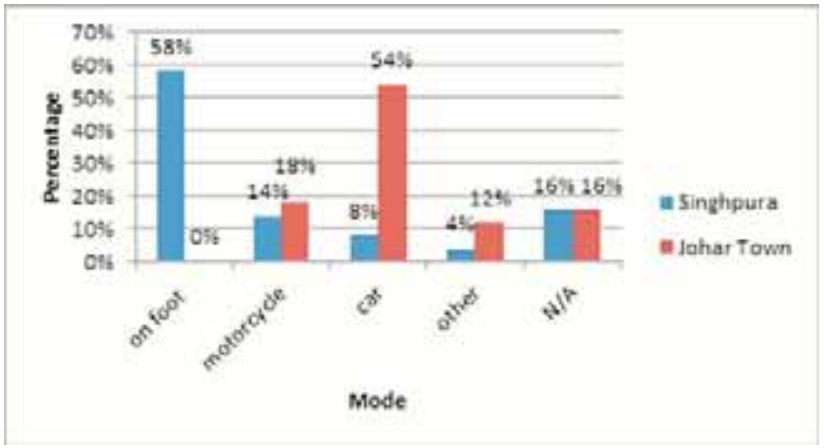

Figure-9: Mode of transport used for going to school.

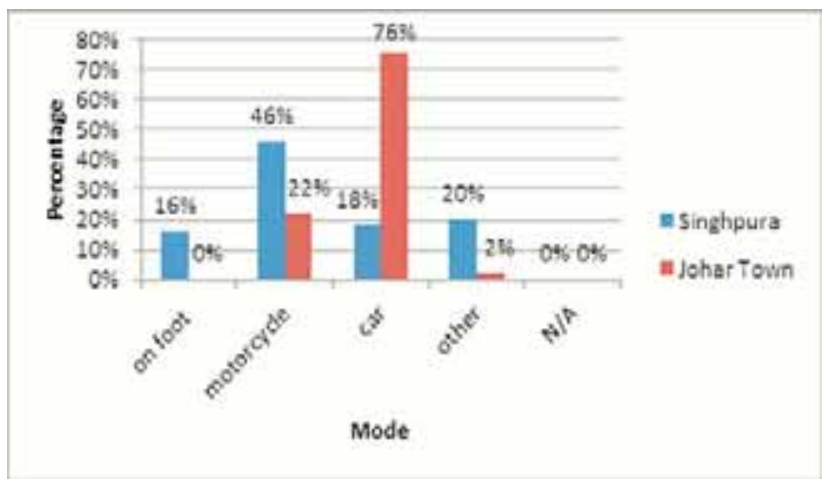

Figure-11: Mode of transport used for getting to workplace. 
Average distance from the house to the main market and
mode of transport used for accessing the market

The main market is a place where residents do grocery shopping. If the market is located at a far distance it can create problems for residents and people will be dependent on personal vehicles for getting to the markets. The statistics that related to location of main market showed that residents of Singhpura had main markets near to their homes. 70\% of the people said that they had markets located at a distance of less than $1 \mathrm{~km}$. In Johar Town, majority of the people had main markets at a distance of 4-6kms and only $18 \%$ of the respondents had markets located at less than $1 \mathrm{~km}$ (Figures 12 and 13). This meant that residents in Singhpura used other sources of transport like auto rickshaws for getting to the market or went on foot, but in the case of Johar Town, people were mostly car dependent and went to the main markets in cars or on bikes.

\section{Average distance from the house to the general shops and mode of transport used for general shopping}

The statistics for location of general shops indicated that in Singhpura all residents had grocery shops located at a distance of less than $1 \mathrm{~km}$ and went to those shops on foot. In Johar Town, $56 \%$ of the shops were located at a distance of less than $1 \mathrm{~km}$ and $42 \%$ were located at a distance of 1$3 \mathrm{kms}$. Due to this season, some residents of Johar Town used their personal vehicles for getting to general grocery shops as well (Figures 14 and 15).

\section{Recreaction Facilities}

\section{Average distance from the house to the place of recreation} and mode of transport used

The statistics of average distance between house and recreational areas revealed that in Singhpura $100 \%$ of the

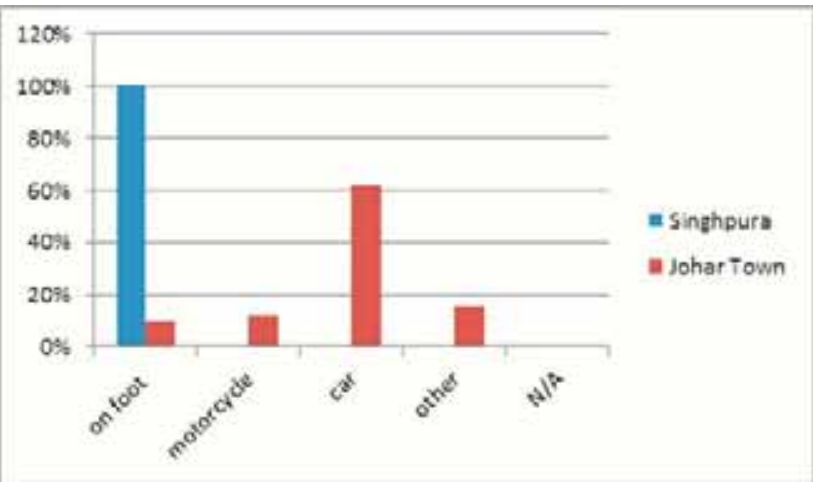

Figure-15: Mode of transport used for going to general grocery shops.

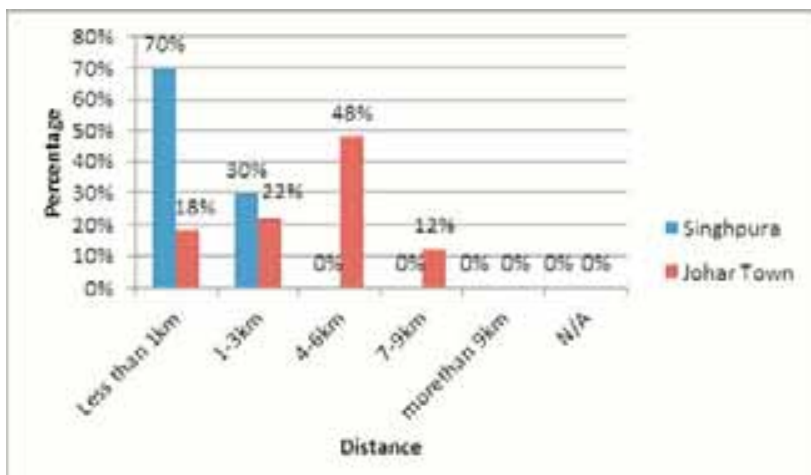

Figure-12: Average distance from the house to the main market.

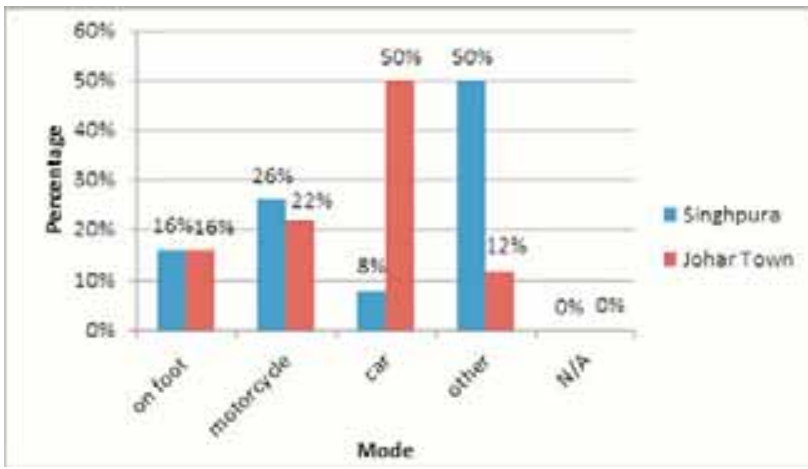

Figure-13: Mode of transport used for going to the main market.

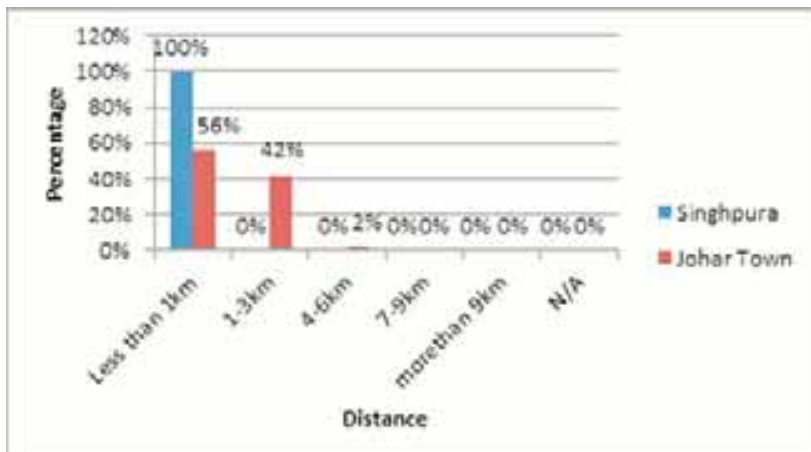

Figure-14: Average distance from the house to the general grocery shops.

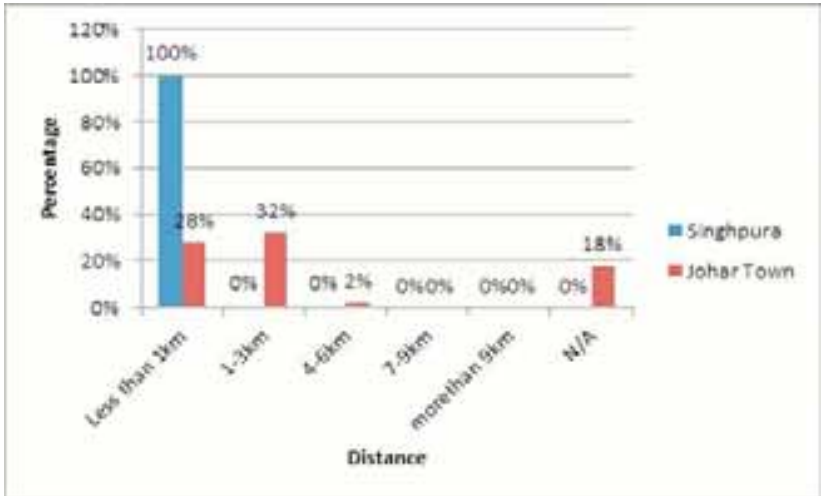

Figure-16: Average distance from the house to the park. 
residents had recreational places, like parks at a distance of less than $1 \mathrm{~km}$ and they could easily walk to these places. In Johar Town, parks and recreational places were located at a distance of 1-3 kms. Therefore, majority of the respondents used their personal vehicles to visit parks, while $32 \%$ of the respondents found these places to be at a walkable distance (Figures 16 and 17).

\section{Average distance to bus stops and mode of transport used}

The statistics related to the distance between houses and bus stops indicated that Singhpura residents had a bus stop at a distance of $1-3 \mathrm{kms}$ from their homes therefore majority of them found bus stops accessible on foot. In Johar Town, majority of the residents did (72\%) not use public transport and only $28 \%$ said bus stops were located at a distance of less than $1 \mathrm{~km}$. Residents who used public transport in Johar Town accessed the bus stop via personal vehicles or on rickshaws (Figures 18 and 19).

\section{Average distance, transport mode used and frequency of visiting cinema}

The statistics related to the average distance to the cinema revealed that in Singhpura none of the respondents went to cinemas. But in the case of Johar Town, because people

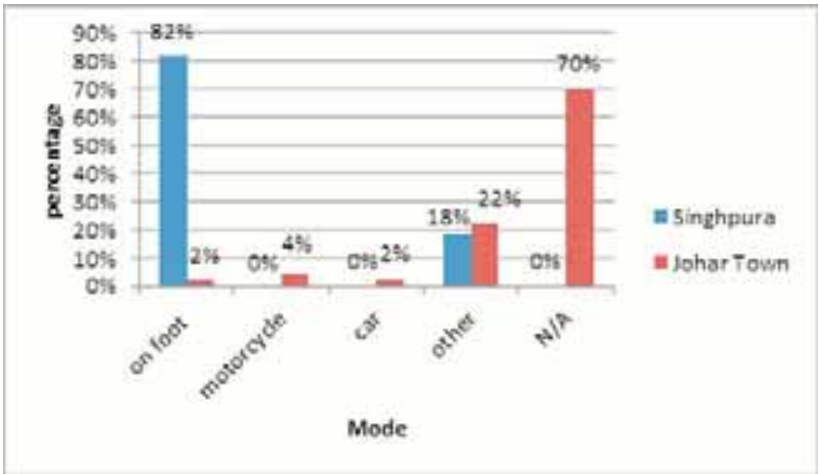

Figure-19: Mode of transport used for getting to the bus stops.

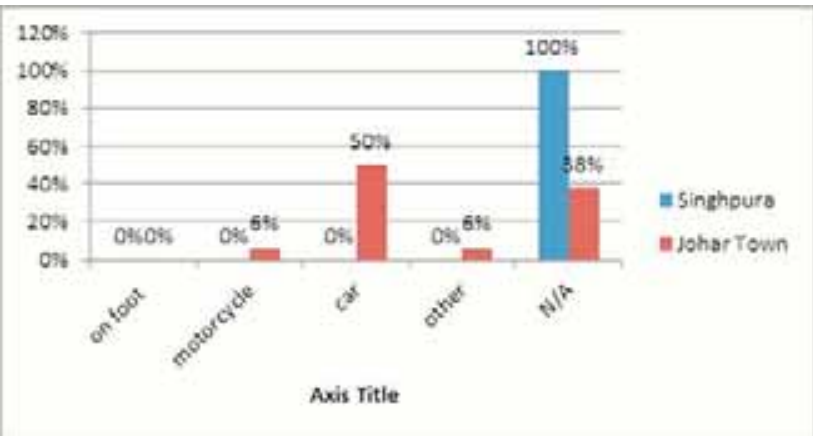

Figure-21: Mode of transport used for getting to the cinemas.

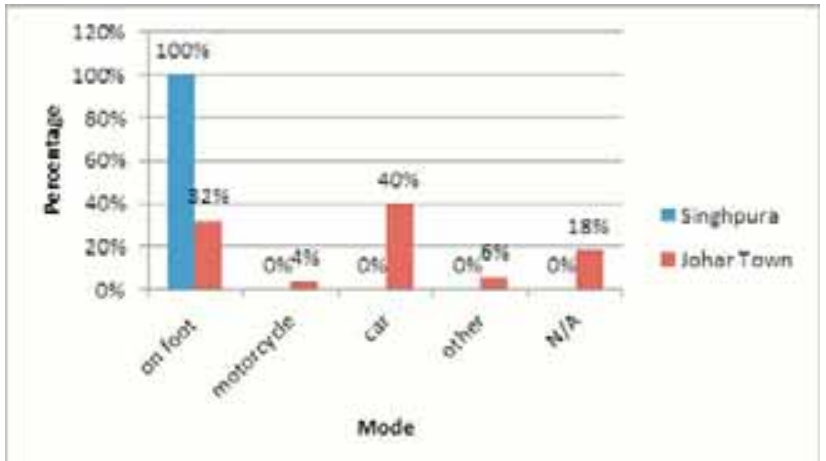

Figure-17: Mode of transport used for getting to the park.

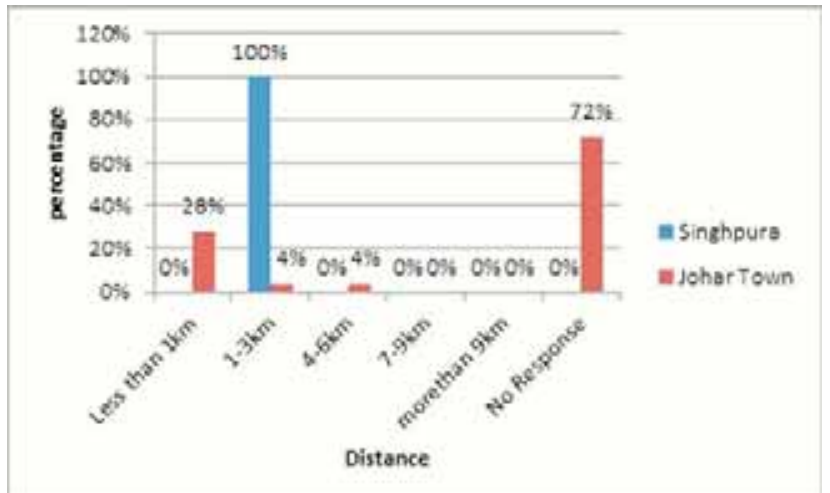

Figure-18: Average distance from the house to the bus stops.

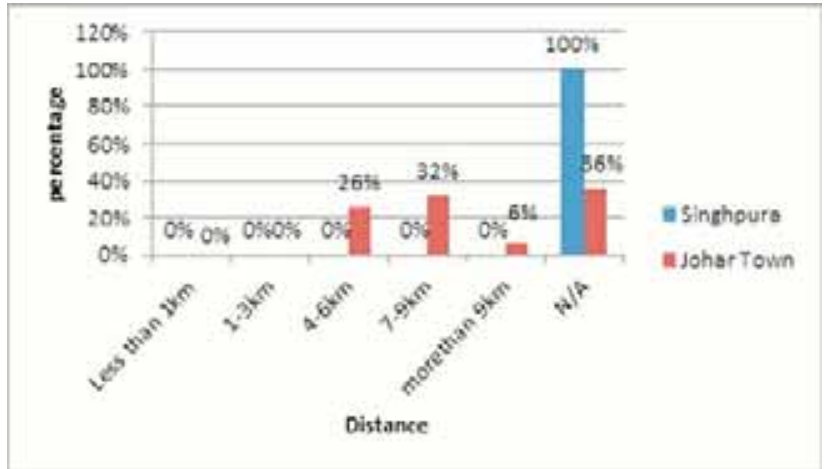

Figure-20: Average distance between houses and cinemas.

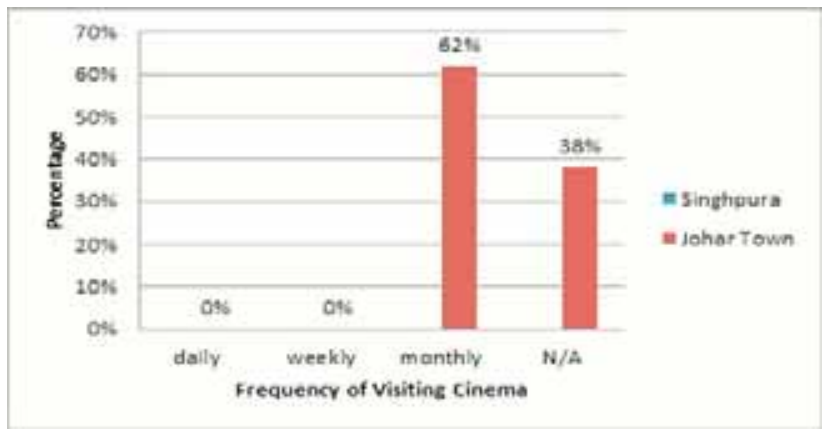

Figure-22: Frequency of people visiting the cinemas. 
belonged to high income group, frequenting the cinema was a norm. $26 \%$ of the respondents of Johar Town had cinemas located within $4-6 \mathrm{~km}$ from the house, $32 \%$ had cinemas located within $7-9 \mathrm{~km}$, while $6 \%$ had cinemas located within $9 \mathrm{~km}$. The respondents used private vehicles to access the cinemas and went to the movies on a monthly basis (Figures 20, 21 and 22).

\section{Average distance, mode of transport used and frequency of visiting stadium and gymnasiums}

The statistics related to residents visiting stadium and gymnasiums indicated that in Singhpura residents did not use these facilities because of unaffordability. There was no

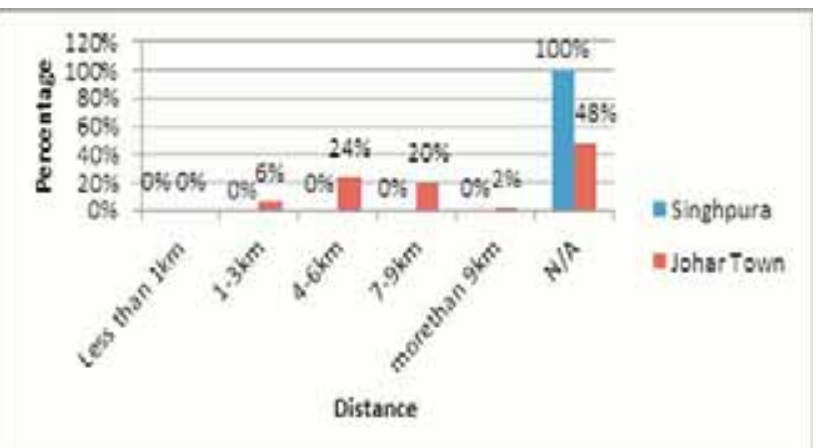

Figure-23: Average distance from the house to the stadium or gymnasium.

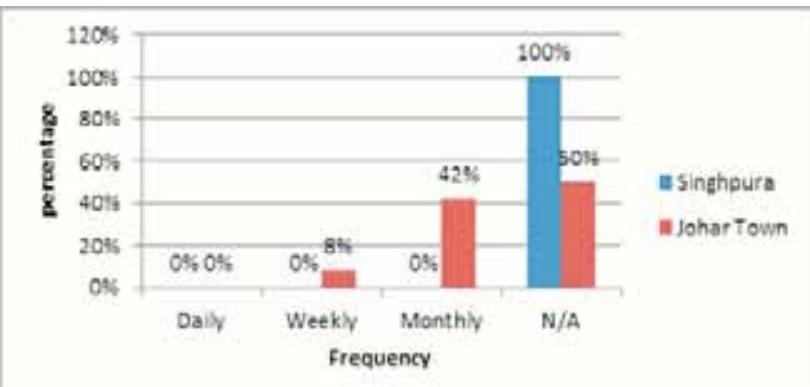

Figure-25: Frequency of visiting the stadium or a gymnasium.

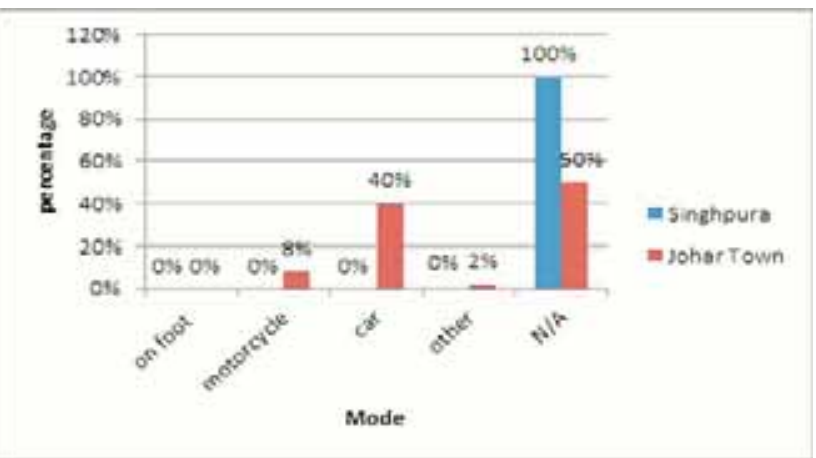

Figure-27: Mode of transport used for visiting the sports club. provision of a stadium or a gymnasium in Singhpura. In Johar Town, $24 \%$ of the respondents frequented the stadium or gymnasium located at a distance of 4-6 km, which they accessed by private vehicles (Figures 23, 24 and 25).

\section{Average distance, mode of transport used and the frequency of people visiting the sports club}

The analysis showed that there was no sports club present in Singhpura, while in Johar Town $6 \%$ of the respondents visited the sports club located within $1-3 \mathrm{~km}$ of their home. $24 \%$ of the respondents said that a sports club is located within $4-6 \mathrm{~km}$ of their house, while $2 \%$ said that the distance

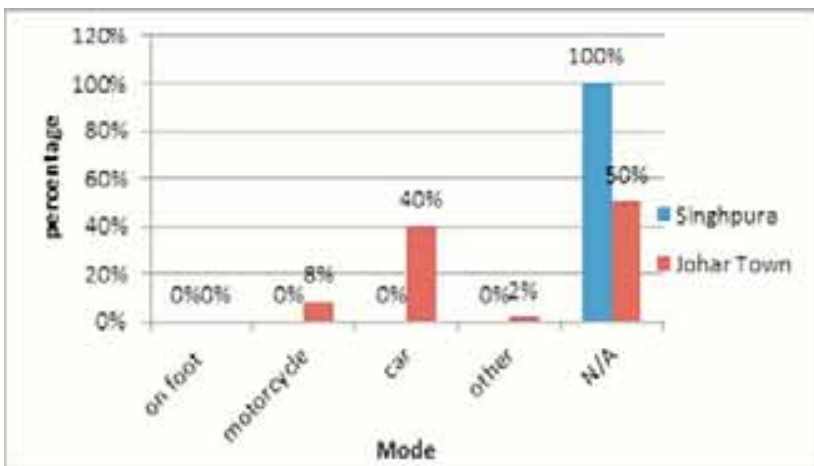

Figure-24: Mode of transport used for accessing stadium or a gymnasium.

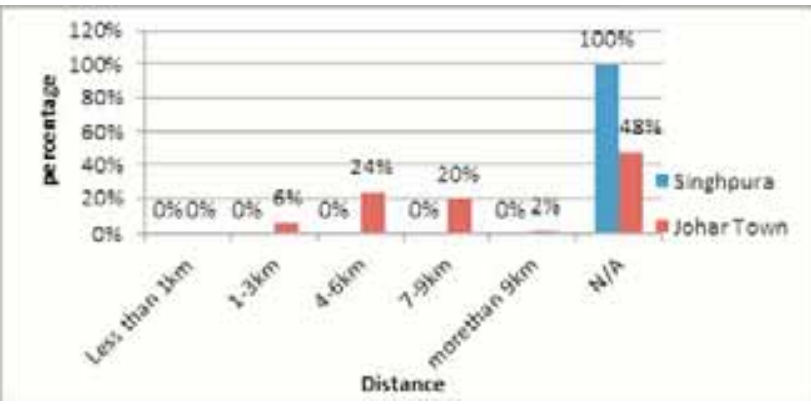

Figure-26: Average distance from the house to the sports club.

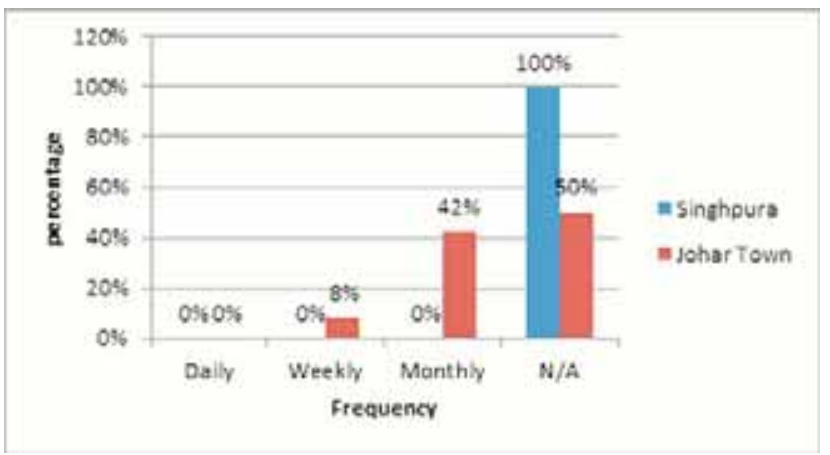

Figure-28: Frequency of visiting the sports club. 
to the sports club was more than $9 \mathrm{~km}$ from their house. Majority of the people who visited the sports club used their personal vehicles and majority of the respondents said that the frequency of visiting sports club was monthly (Figures 26,27 and 28).

\section{Transport Ownership}

The statistics of transport ownership indicated that in Singhpura majority of the respondents had their own motorbikes. People also used bicycles for commuting in Singhpura but the percentage was only $4 \%$. Respondents of Johar Town had a large ownership of cars with almost $80 \%$ of the people in Johar Town having their own cars. In Singhpura car ownership was only 18\% (Figure 29).

\section{Frequency of contact with friends and neighbours}

A study of the connection between neighbours showed that the people were generally interested in social ties. The statistics related to the frequency of contact with friends and neighbours indicated that in Singhpura people interacted with friends and neighbours on a daily basis. Every day they met each other and spent some time. In Johar Town, only $10 \%$ of the people met with the neighbours on a daily basis and majority of them said they interacted with neighbours and friends on a monthly basis (Figure 30 ).

\section{Place of interaction with neighbours}

In Singhpura majority of the residents interacted with each other on the streets (96\%). In Johar Town majority of the residents met in parks (Figure 31).

\section{Place for community meetings}

These statistics indicated that $34 \%$ of the people in Singhpura met for community meetings in the mosque. In the case of Johar Town, $56 \%$ of the people did not participate in community meetings but few of them had community

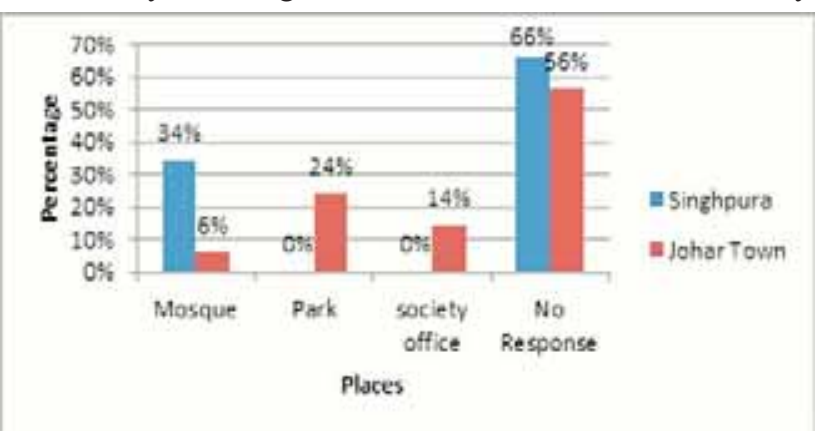

Figure-32: Place for community meetings.

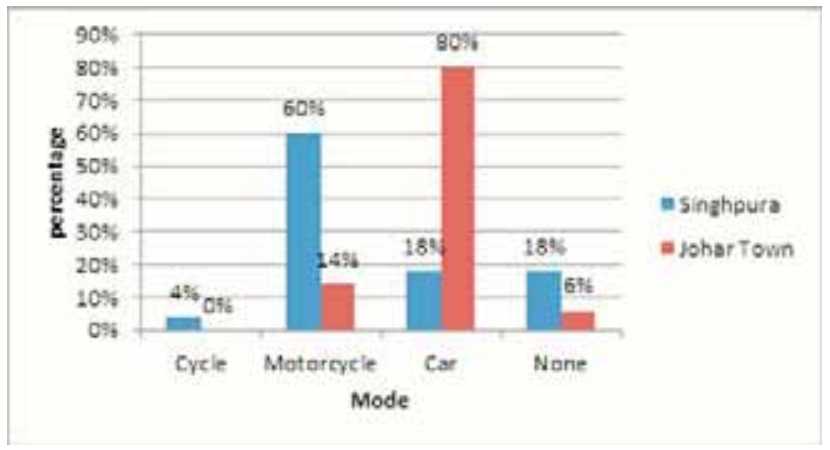

Figure-29: Transport ownership in the two neighborhoods.

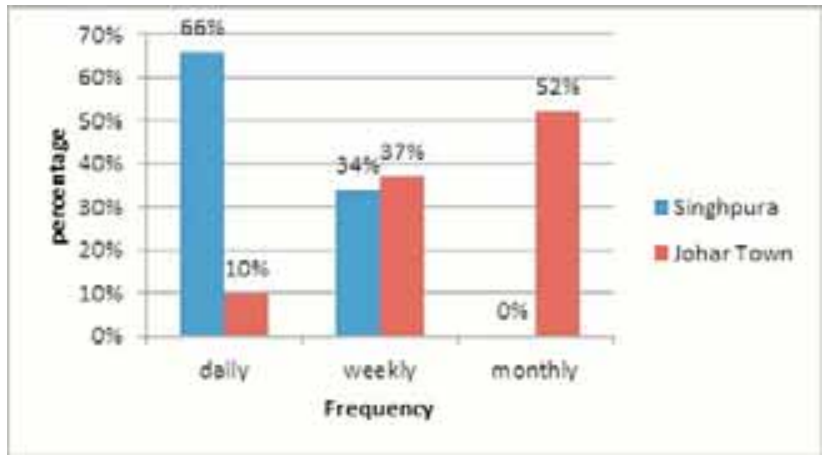

Figure-30: Frequency of contact with friends and neighbours.

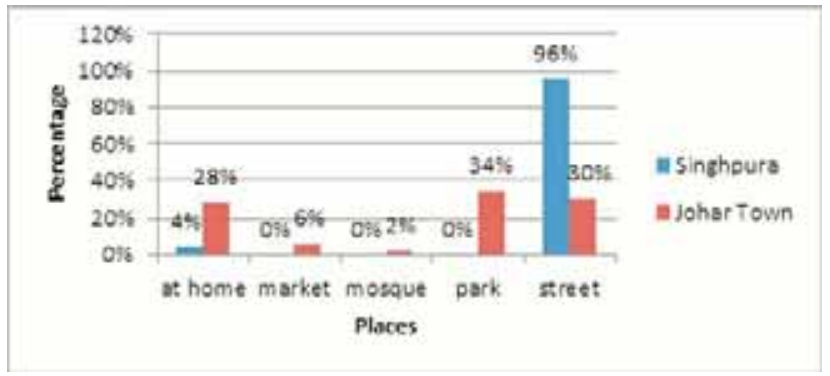

Figure-31: Place of interaction with neighbours.

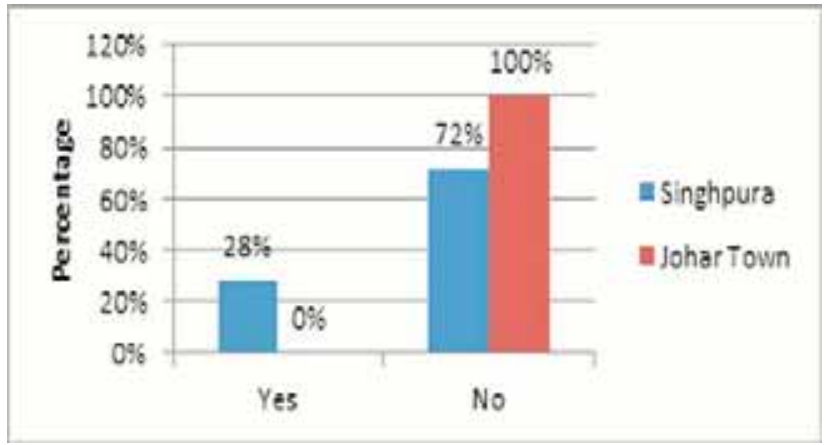

Figure-33: Community led development project. 
meetings in the park or in the society office (Figure 32).

\section{Community Participation}

\section{Community level development project}

In response to this question $28 \%$ of the respondents from Singhpura said that communiy led development projects existed in Singhpura and 100\% respondents from Johar Town said there had been no community level development project in the past (Figure 33).

\section{Involvement in community led development project}

Most of the respondents did not participate in any community led development projects in both Singhpura and Johar Town. Only $28 \%$ of the respondents in Singhpura were affiliated with some form of community development project (Figure 34).

\section{Input in community led development project}

The people who were involved in the community led development projects, $20 \%$ people in Singhpura responded that their input was monetary, while $6 \%$ said that they provided coordination in the project. As there was no community led development project in Johar Town so this question was not applicable on the residents of this area (Figure 35).

\section{Arrangements of festival}

$76 \%$ residents of Singhpura answered in the affirmative to this question and in Johar Town 14\% responded in the

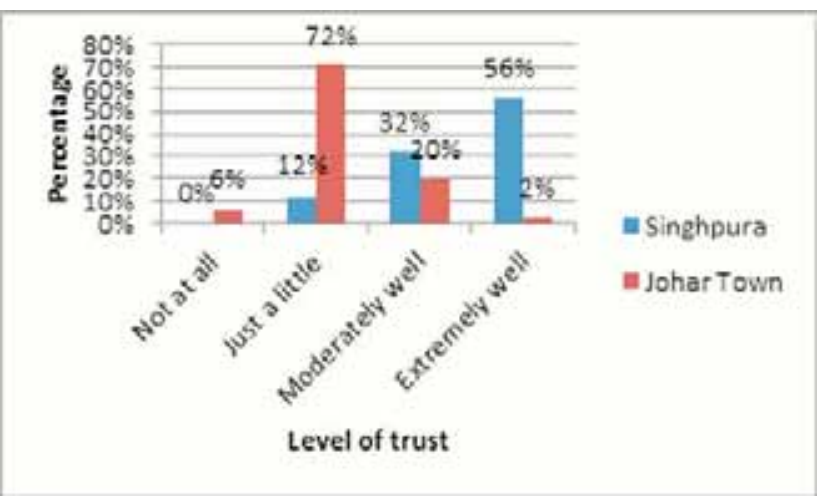

Figure-37: Level of affiliation amongst neighbours.

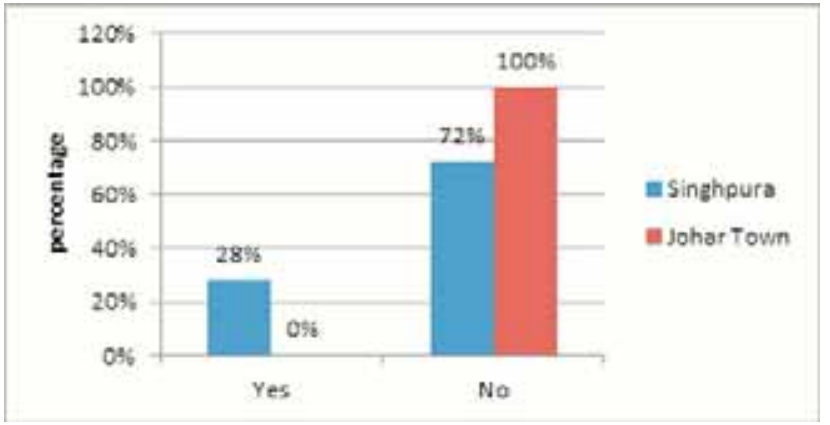

Figure-34: Involvement in community led development project.

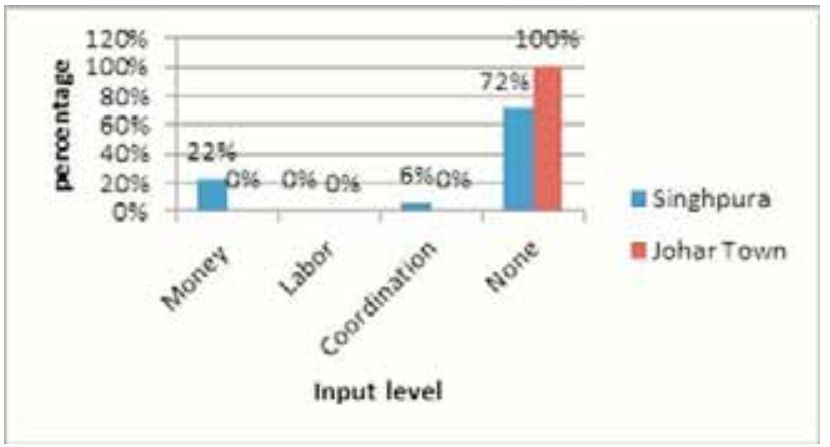

Figure-35: Input in community led development project.

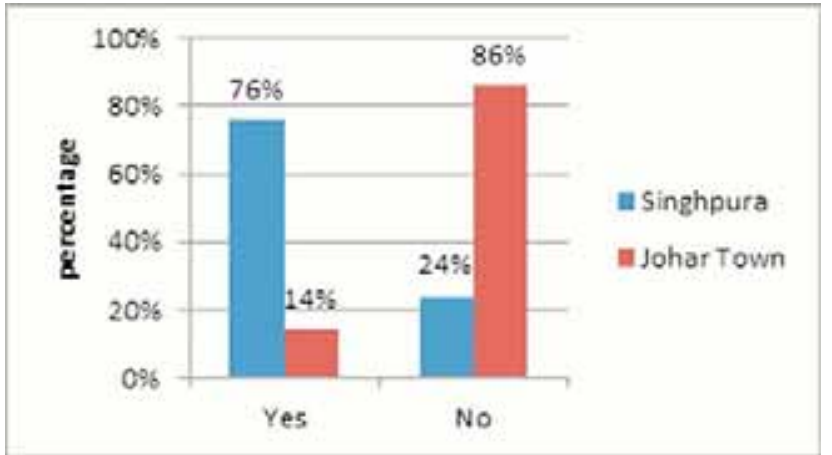

Figure-36: Community level festivals.

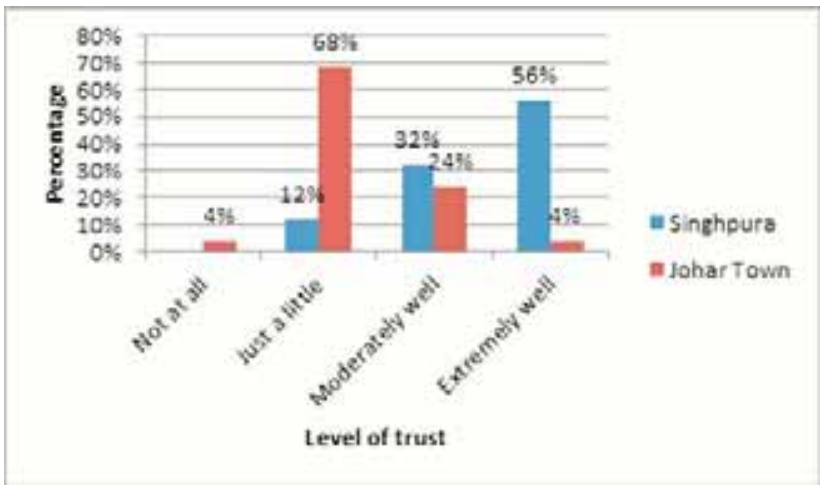

Figure-38: Level of trust amongst neighbours. 
affirmative (Figure 36).

\section{Level of trust within the society}

\section{Contact with neighbours}

In order to find out the familiarity amongst neighbours in planned and unplanned areas a question was asked about familiarity with neighbours. The analysis showed that in Singhpura $12 \%$ of the people barely know their neighbours, $32 \%$ knew their neighbours moderately well, while $56 \%$ knew their neighbours extremely well. While in Johar Town $6 \%$ of the people knew their neighbours well, $72 \%$ knew their neighbours barely and $20 \%$ knew their neighbours moderately well (Figure 37).

\section{Trust on neighbours}

In order to identify what the residents of planned and unplanned areas felt about the level of trust between neighbours a question was asked. $12 \%$ of the respondents from Singhpura said that they had low level of trust, $32 \%$ said that trust level was moderate, while $56 \%$ said that they fully trusted their neighbours. 4\% respondents from Johar Town said that they had no trust on the neighbours, while $68 \%$ said they had low levels of trust, $28 \%$ had moderate trust levels and only $4 \%$ of the respondents highly trusted their neighbours (Figure 38).

\section{Change in the level of trust on neighbours}

After asking the question about the level of trust between neighbours, a question regarding the change in the level of trust in previous few years was asked. 56\% residents of Singhpura said that the level of trust had increased in the previous years, while no one responded that the level of trust had decreased. $44 \%$ of the responds said that the level of trust stayed about the same. $22 \%$ residents of Johar Town responded that the trust level had increased in the previous years, while $58 \%$ said that the trust level had decreased and $20 \%$ said it had remained the same in the previous years (Figure 39).

\section{Crime rate in the area}

When asked about the crime rate and security conditions in the neighborhoods, most of people residing in Singhpura responded that they had low crime rate in the area, while only $10 \%$ said that they had high crime rate. While $68 \%$ residents of Johar Town said that they had high level of crime in the area and $32 \%$ said that they had low level of

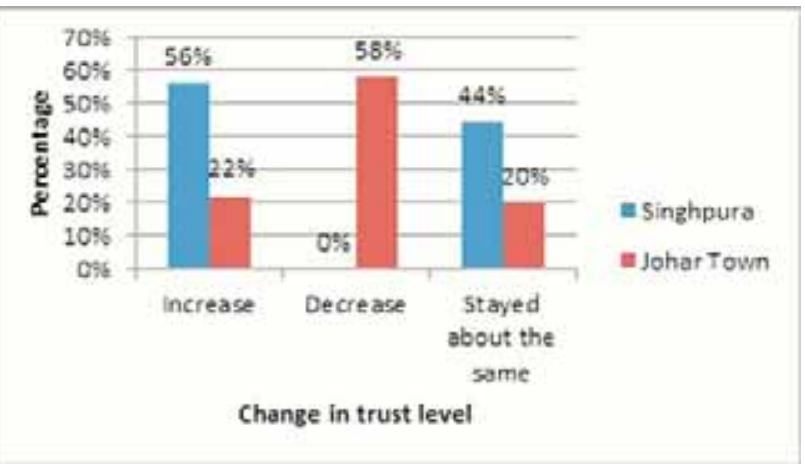

Figure-39: Change in level of trust.

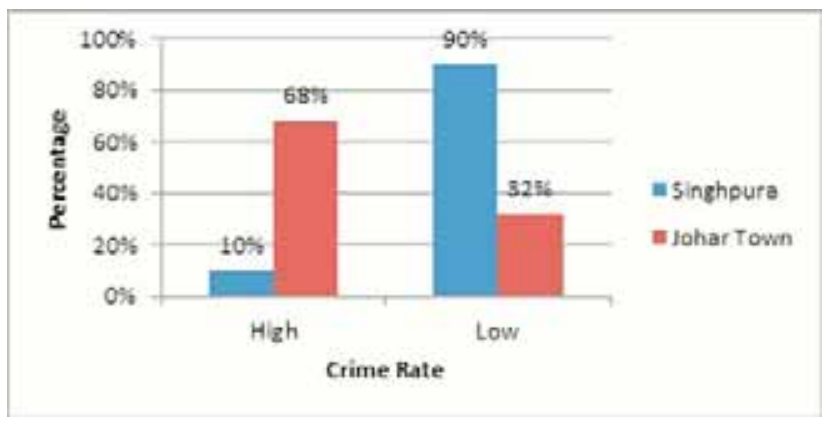

Figure-40: Crime rate in area.

crime (Figure 40).

\section{ANALYSIS AND DISCUSSION}

From the analysis of the survey it was identified that in Johar Town the majority of the residents belonged to high income group, while majority of the residents of Singhpura belonged to low or medium income groups. In Johar Town the majority of the people were engaged in government jobs, but in Singpura majority of the people were self-employed and owned shops or other local business. In Johar Town land uses were totally segregated and average distance from the house to the school, place of occupation and the markets was very high, thus the residents were totally dependent on cars to commute. Due to high dependency on cars residents of Johar Town got very rare chance of interacting with neighbours. As Singhpura is a mixed land use settlement with an organic layout, the daily need facilities were located at walking distance and car ownership was low. The residents either walked or used public transport to reach their destinations, which provided intense chances of interaction amongst residents.

Johar Town is a newly developed area with majority of the residents having shifted to the area in the past 1-10 years. Thus, familiarity with the neighbours was minimal and the level of close bonding was not there. In comparison, residents 
of Singhpura, which is an old locality, had been living there for a long time, knew each other well and had high level of trust amongst them. In Singhpura, people interacted with friends and neighbours on a daily basis. But in Johar Town, people met once a month. That has been identified as one of the reason for decreasing social capital in planned areas. Places for daily meeting in Singhpura were mosques and streets where people interacted with each other easily. But in the case of Johar Town, people met each other in a park or at home only once a month.

Generally, people belonging to high income groups have low level of social capital because they are involved in their business activities and have no time for participation in development projects. In Singhpura, people were willing to participate in such projects. In Singhpura, people arranged community festivals and also attended these festivals. But in Johar Town, as people were busy in their personal lives, they did not give time to such activities. In Singhpura, as people met daily with their neighbours so they knew them well. In Singhpura, the crime rate was low because people knew each other well and had a strong relationship with others. But in Johar Town, there was less interaction among neighbours and streets were empty because people prefered to live in their homes. This was one of the reasons for increase in the crime rate and decrease in social capital.

Social capital is measured with factors like walkability, social interaction and networks, community participation and level of trust (Lin, et. al., 1999; Scheffert, 2009; Svendsen, 2010). Walkability is the most important factor which shows living trend of communities (Shannon, 2013). But this factor is decreasing in neighborhoods of Lahore. Neighborhoods are being designed which promote dependency on personal vehicles. This is a major issue with high income communities where people mostly use personal vehicles like cars for travel. In old developed areas, which are usually unplanned areas of Pakistan, all the facilities are available within walking distance. People easily walk to get things of daily use. Dependency of high income communities on vehicles decreases the walkability factor and ultimately becomes one of the reasons for the decrease in social capital. Social interaction helps to create a sense of community (Unger and Wandersman, 1985; Leyden, 2003; UN Habitat, 2014). If people of a community have high interaction amongst them, a sense of community and family develops and other members and new residents feel welcomed into the neighborhoods. Well defined networks also create ways for interaction with people of a community. Mostly people who live in unplanned areas have a high level of walkability and get a chance to interact with their friends and neighbours daily. This helps them to understand and support each other. These people have strong bonding and bridging ties amongst them. They all have same social norms and values. But in planned areas, social interaction seems to be decreased. People in these neighborhoods are more involved in their personal activities and social interaction decreases in these communities and so does the social capital.

Trust is the prime most factor that helps a community to succeed (Nelson, et. al., 2003; Stephenson, 2004; Lisa, 2012). The trust level between people increases with number of meetings. In neighborhoods of Lahore trust amongst people is decreasing gradually. People are losing trust on each other and other governmental agencies. In unplanned areas where connectivity of streets is high and people prefer walking to reach their destinations, some level of trust is still there. Due to high level of walkability they get the chance of meeting neighbours daily and get the chance to know what is going on in their life. They share incidents with each other which increases trust amongst people and it also increases the probability that the neighbours will help each other if they are in need. In planned areas of high income residents people prefer to stay indoors due to increased security concerns. This decreases the level of trust amongst people which in turn decreases the social capital.

Community participation is that component of social capital which is concerned with people's interest in the development of a community and the country at large (Talen, 1999; UN Habitat, 2014). If people participate in development projects, the economy level of the country increases and this improves the living condition of people. In unplanned areas people are more willing to participate in development projects as compared to planned schemes. Because of participation in development projects, people get a sense of ownership in the projects and try to maintain them in future. In developed countries due to high social capital people participate in community development projects, but in the case of Pakistan due to low level of social capital people are not involved in any development related activity and there is no concept of participatory development. Those who do not take part in development of projects of community have no sense of ownership of the projects and do not care about these facilities. Thus the decrease of interaction among people results in decrease of social capital.

\section{CONCLUSIONS AND RECOMMENDATIONS}

Based on the findings of this research some recommendations can be put forward with regards to new urban development. These developments should be done in a manner where 
developments are based on new urbanism principles which encourage the use of undulating and straight streets that maximize pedestrian connectivity, are a mix of compatible uses and work to incorporate elements such as architectural detail and street furniture that encourage human interaction. Pattern of land use should be based on such design where people can meet each other like providing for parks, open spaces and community halls. Areas and streets should be safe for traveling, as this will encourage meeting neighbours and friends without fear. Neighborhoods should be car independent where people can move freely. Developers should arrange and provide spaces for community festivals and events, which attract people and also enhance community interaction.

Each neighborhood should have a mix of land uses and densities that provide options to live, learn, work and play. Intensive land uses connected and focused around alternative transportation modes should be developed. Citizens should be able to access daily shopping and recreational needs in their neighborhoods easily, regardless of choice of mode.

Urban neighborhoods can be designed to be self-sufficient in terms of reducing the need to travel by encouraging walking and by providing opportunities for work and recreation closer to home. Streets should be designed for pedestrian and cyclist safety. When people are encouraged to use streets rather than being dependent on cars, a sense of ownership of resources is developed and people become socially connected with neighborhoods and get a chance to interact with neighbours. This ultimately will result in generation of social capital and in turn the development to become sustainable.
Each neighborhood should offer high quality of public spaces, with a variety and mix of leisure and recreational opportunities. Open spaces should be connected and integrated. Public spaces should be accessible and suitable to a range of ages and abilities. Active and passive spaces should be provided to congregate, socialize, and for recreation to encourage people to be physically active and spend time outdoors.

Each neighborhood should be designed to promote citizens health and well-being and increase overall neighborhood safety and social interaction. Gated community should be promoted for purpose of safety. Clear boundaries of neighborhood should be demarcated to enhance functional and social interaction, sense of community and identity within the boundaries.

For enhancing of social capital, a concept of social mix should be created by mixing social classes, combining house types and tenures. Neighborhoods should provide a mixture of buildings in terms of unit sizes and housing types. Housing options should be provided within neighborhoods, appealing to a range of incomes, family types and opportunities. There should be a better balance of demand for community services and facilities and opportunities for life time communities should be provided.

Conclusively, urban development process should follow the principle of public participation because this increases a sense of community and creates the potential for a continuous quality of interaction. Public participation also helps designers to become conscious of the desires of potential users, allowing them to create a satisfying environment designed to accommodate resident needs. Developers should also consider

\section{REFERENCES}

Baron, S. et. al., (eds.), 2000, Social capital: Critical perspectives, Oxford University Press, Oxford.

Coleman,J.S., 1994, Foundations of social theory, Belknap Press, Cambridge MA.

Coleman,J.S., 1988, 'Social capital in the creation of human capital', American Journal of Sociology, Vol. 94, 95-120.

Harper, R., 2002, The measurement of social capital in the United Kingdom, Office of National Statistics, London.

Haq, N. U., 2010, Social capital in Pakistan, viewed 3 June 2015, from

www.development20.blogsppot.com/2010/01/spcoa;_capita;_in_paksitan.html.

Leyden, K. M., 2003, 'Social capital and built environment: importance of walkable neighborhood', American Journal of Public Health, Vol 93, No. 9: 1546-1551. 
Lin, N., Cook, K., et.al (eds.), 1999, Social Capital: Theory and Research. Aldine Transaction, New Jersey. Lisa, B. G., 2012, 'Streets apart: Does social capital vary with the neighborhood design?', Urban Studies Research, Vol 11, 336-371.

Nelson, B., et.al., 2003, How to build social capital across communities? UCLA School of Public Policy and Social Research, Los Angeles.

Pretty, J., and Ward, H., 2001, 'What is social capital?' World Development, 29 (2), 209-227, University of Essex. Putnam, R.D., 2000, Bowling alone: The collapse and revival of American Community, Simon \& Schuster, New York. Scheffert, D., 2009, Social capital and our community, The University of Minnesota Extension Center for Community Vitality, Minneapolis.

Shannon, K. C., 2013, 'Social capital and walkability as social aspect of sustainability', Sustainability, Vol 5, 3474-3483.

Stephenson, C. A., 2004, Trust, social capital and organizational effectiveness, Blacksburg, Virginia Svendsen, G. L., 2010, 'Socio-spatial planning in the creation of bridging social capital: The importance of multifunctional centers for intergroup networks and integration', International Journal of Social Inquiry, Vol 3: 2, 45-73.

Talen, E., 1999, 'Sense of community and neighborhood form: an assessment of the social doctrine of New Urbanism', Urban Studies, Vol. 36, 1361-1379.

UNHabitat, 2014, 'Urban Planning and Design for Social Capital', in Vilar, K., 2015, Urban design and social capital in slums. Case study: Moravia's urban planning and architecture design for sustainable development, UPADSD 14-16 October, 56-67.

Unger, D.G. and Wandersman, A., 1985, 'The importance of neighbors: the social, cognitive, and affective components of neighboring', American Journal of Community Psychology, Vol. 13, 139-170. 